\title{
Narrativas de estrada e o sertão na literatura e no cinema brasileiros contemporâneos
}

\author{
Juliana Santini ${ }^{*}$
}

Discutindo a imagem do sertão como uma das matrizes culturais retomadas pelo cinema nos últimos anos, Walnice Nogueira Galvão propõe que, no que diz respeito às produções cinematográficas do final do século XX e do início do XXI, é preciso que haja uma leitura capaz de considerar que o cinema não estaria, novamente, fazendo uso da matriz literária regionalista:

[...] até quando deveremos buscar as origens dessas metamorfoses na ficção regionalista, que no passado inspirou as câmeras? Nossa literatura veio adquirindo um cunho acentuadamente urbano e até metropolitano que repercute no cinema. Já os filmes não dão mostras de olhar para trás, parecendo, ao contrário, sondar o futuro (GALVÃo, 2004a, p. 5).

A sugestão de dissociar a interpretação do lugar ocupado pelo sertão no cinema brasileiro contemporâneo da literatura regionalista que, em diferentes momentos, serviu-lhe de substrato, é instigante na medida em que parte de uma suposta desvinculação associada a uma questão temática: a literatura brasileira dos últimos anos, com um "cunho acentuadamente urbano", não seria a fonte de filmes nacionais que colocam em cena o sertão ou a figura do cangaceiro, somando a isso o fato de que o próprio cinema não estaria "olhando para trás" e buscando um paradigma literário de representação com bases no romance de 30, como fizeram, em larga medida, o Cinema Novo e o filme de cangaceiro, por exemplo. Em texto também publicado em 2004, em que realiza uma reflexão menos sintética sobre a evolução do sertão na história do cinema, a autora deixa mais clara a hipótese:

O Regionalismo literário da atualidade, não mais ocupando o centro da cena como em seu apogeu nem tendo o prestígio de que já desfrutou, continuou a ser praticado em caráter de diluição, seja pelos mesmos autores quando ainda vivos até há pouco, seja por outros que vieram depois (GALVÃo, 2004b, p. 391).

Mais de uma década depois dessa interpretação, que se reconhece ainda inconclusa porque dependente do que viria a ser o quadro constituído pelas produções

Doutora em Estudos Literários e professora do Departamento de Literatura da Universidade Estadual Paulista (Unesp), Araraquara, SP, Brasil. E-mail: jsantini@fclar.unesp.br 
cinematográficas e literárias dos anos vindouros, a relação entre os significados mobilizados pela imagem do sertão no cinema e na literatura ainda carece de uma reflexão mais abrangente, que leve em conta as nuances de sentido adquiridas pelo tema na narrativa literária dos últimos anos e o modo como a filmografia brasileira, especialmente das primeiras décadas do século XXI, tem sido ou não permeável a essas nuances.

A leitura que aqui se apresenta coloca em perspectiva o conto "Milagre em Juazeiro", que faz parte do volume Livro dos homens, publicado em 2005 por Ronaldo Correia de Brito, e Viajo porque preciso, volto porque te amo, filme produzido por Marcelo Gomes e Karim Aïnouz em 2009, partindo da constatação de que há, tanto na literatura quanto no cinema dos últimos vinte anos, uma significativa recorrência de narrativas que articulam a imagem do sertão à figura da estrada e ao motivo do deslocamento. Entram em discussão, assim, as viagens realizadas por três personagens pelo sertão: no filme, o geólogo José Renato atravessa o sertão para realizar um trabalho de mapeamento do solo que servirá como estudo sobre a viabilidade de transposição de um rio por aquela região; no conto, Maria Antônia e seu marido Afonso, médicos de Recife, viajam em um caminhão de romeiros rumo a Juazeiro, em jornada definida pela moça, que espera encontrar a avó, que não conhece, na festa em louvor a Padre Cícero. Nos dois casos, o espaço é semantizado pela experiência individual, ao mesmo tempo que determina a construção de significados para a constituição do personagem em sua própria experiência.

\section{A estrada entre o documentário e a ficção}

Em entrevista a Jean-Claude Bernadet (2010), por ocasião do lançamento de Viajo porque preciso, volto porque te amo, Marcelo Gomes e Karim Aïnouz situam a gênese do longa em projeto de 1997, cujos objetivos eram a realização de uma pesquisa sobre as feiras do sertão e a reposta a uma questão: "Que relação tinham as feiras do sertão com as de outros lugares do mundo?”. Filmadas em 1999 e com mais de quarenta horas de duração, as entrevistas desse primeiro projeto foram editadas em 2003, compondo o documentário Sertão de acrílico azul piscina, lançado em 2004 no âmbito da série "Brasil 3x4" - Rumos Itaú Cultural Cinema e Vídeo 2003-2004. A retomada desse material em um trabalho que não fosse o do documentário daria origem, então, à produção de 2009.

Note-se nesse caso que Viajo porque preciso é uma narrativa que se constrói na fronteira entre o documentário e a ficção. No filme, o personagem José Renato, que narra sua história enquanto viaja pelo sertão, é uma voz adicionada às imagens editadas: sem se mostrar em suas feições em nenhum momento da narrativa, o geólogo funciona como a mediação subjetiva criada entre a realidade e a sua representação - uma vez posta, essa voz determina o olhar que enovela o factual, proveniente do dado documental, e a fabulação criada pelo relato. Sem corpo, o 
personagem José Renato é essencialmente perspectiva subjetiva, materializada na voz narrativa responsável por alinhavar o dado externo - o sertão "objetivo" a uma experiência individual determinada pela relação com o espaço.

O filme começa com a focalização de uma estrada, em tomada do interior do veículo em movimento, de modo que se tem a imagem da rodovia vista de dentro do para-brisa do automóvel. Como se trata de uma tomada noturna, vê-se apenas a porção da estrada iluminada pelo farol do automóvel, que ocupa uma faixa de pouco menos da metade da tela, sobre a qual se impõe o plano superior escuro. O rádio do carro toca "Sonhos", em versão interpretada por Peninha, a quem cabe a letra da música. O negro da noite e a pista iluminada são quebrados apenas por placas de sinalização, que brilham com a luz nelas refletida: em uma sequência de mais de um minuto, nenhuma interferência de outro carro vindo em sentido contrário. Sem qualquer palavra de José Renato, a perspectiva objetiva do espaço focalizado pela câmera é rasurada pela trilha sonora - música que faz parte do que se pode arbitrariamente tomar como "música brega brasileira" - e por uma solidão que preenche a cena pela soma do vazio da estrada ao tema do amante abandonado ecoando na música, apesar de o espectador não ter acesso, nesse primeiro momento, ao fato de haver ou não um passageiro ao lado do motorista.

Um corte, aos 2 minutos e 24 segundos, inicia uma tomada idêntica, agora com luz diurna. É nesse ponto que o sertão aparece às margens da rodovia e, com o rádio desligado, a voz de José Renato faz um inventário objetivo dos instrumentos que carrega. Em sequência que se estende novamente por mais de um minuto, apenas uma caminhonete da polícia rodoviária e uma moto em sentido contrário. Nenhuma casa ou posto de serviços. Um novo corte, aos 3 minutos e 38 segundos, opõe o movimento das duas sequências iniciais a uma imagem que parece congelada, em que se vê, do interior do automóvel e a partir da janela da porta do motorista, duas casas muito simples envoltas por vegetação ressequida. A impressão de quadro imóvel é anulada pelo movimento sutil do mato no acostamento e interrompida pela frase: "Parada pra mijar. Eita vontade de voltar" (VIAJO..., 2009).

O monólogo de José Renato ao longo da viagem evoca a figura de Galega, que se coloca como uma espécie de interlocutora in absentia. Essa construção evidencia não apenas a solidão anunciada, na cena inicial, pela combinação da estrada vazia e da trilha sonora, mas também a situação de crise do personagem, que se vê diante do fim de seu relacionamento com a mulher. Estreita-se, novamente, a relação entre objetividade e subjetividade na narrativa: a jornada pelo sertão existe inicialmente em função do trabalho de Renato, que fará um estudo geológico da região - e o dado objetivo dessa empreitada fica evidente pela lista de materiais enumerada em sua primeira fala -, mas dela se projeta um isolamento emocional que corresponde ao enfrentamento de si mesmo.

Nesse ponto é importante que sejam questionados os imbricamentos engendrados pela articulação entre a forma do road movie e o espaço do sertão no filme de Karim Aïnouz e Marcelo Gomes. Samuel Paiva (2011, p. 48) destaca o ponto de 
vista de Walter Salles, para quem "os filmes de estrada se relacionam com crises de identidade de personagens que, por sua vez, expressam a crise das próprias culturas nacionais". Diante dessa perspectiva, parece interessante que seja relembrada a proposição de Ismail Xavier (2012) no prefácio à segunda edição de Alegorias do subdesenvolvimento: a necessidade de observação das alegorias nacionais criadas pela produção cinematográfica das décadas de 60 e 70 em sua revisão pelo cinema contemporâneo.

Viajo porque preciso, volto porque te amo faz parte de um conjunto de narrativas mais amplo que, desde finais dos anos 1990, colocam a estrada do road movie a cruzar o sertão brasileiro. Central do Brasil, de 1998, já havia feito do caminho para o interior do país a imagem da procura de reconhecimento do personagem: o menino Josué parte do Rio Janeiro para o Nordeste com Dalva, que vivia de escrever cartas aos passageiros da estação Central do Brasil. O percurso tem início em um não lugar, ${ }^{1}$ o maior terminal de trens do Rio de Janeiro, o que determina a construção da metáfora da viagem como busca, uma vez que o "aqui" de onde se sai, espaço de passagem, não permite o delineamento de qualquer identidade. O ponto de destino dessa jornada, o "lá" que determina a crença na existência de um melhor - Josué procura o pai para quem a mãe enviara uma carta escrita por Dora antes de morrer em um acidente de carro - é nesse caso o sertão nordestino, que se traveste da utopia de uma vida melhor.

Em Central do Brasil o sertão aparece sem a construção alegórica da revolução que Ismail Xavier identificou no Cinema Novo de Deus e o diabo na terra do sol, com a composição de um questionamento da força popular e do destino das determinações da história que parte de um conjunto complexo de relações estabelecidas pela narrativa no interior da própria ideia de revolução (XAVIER, 2007, p. 137-138). Como produção emblemática da Retomada, o filme de Walter Salles põe em primeiro plano um sertão que é, por um lado, semantizado pela esperança da reconstrução: Josué não encontra o pai, mas é acolhido pelos dois irmãos mais velhos em um lugar - no sentido que Marc Augé (2012) dá ao termo; ${ }^{2}$ por outro lado, há que se notar que esse mesmo sertão é posto como o espaço da desigualdade, território de abandono e de pobreza.

Esse processo de ressemantização do sertão, de cujo início Central do Brasil dá notícia no cinema brasileiro, encontra no road movie um ponto de sustentação que

\footnotetext{
Ao tratar da definição dos não lugares como marca de uma supermodernidade que apaga a identidade do sujeito em espaços públicos de trânsito, como estações, aeroportos e rodoviárias, esse apagamento se daria como uma espécie de borrão nos contornos da individualidade e de qualquer possibilidade de particularização, como ocorre com a homogenização de comportamentos realizada por grandes redes de hotéis ou de lojas. Em um não lugar, o aqui e o agora são anulados em sua especificidade relativa a um espaço outro ou a um tempo outro: "Se um lugar pode ser definido como identitário, relacional e histórico, um espaço que não pode se definir nem como identitário, nem como relacional, nem como histórico é um não lugar" (AUGÉ, 2012. p. 73).

2 'O termo 'espaço', em si mesmo, é mais abstrato do que o de 'lugar', por cujo emprego referimonos, pelo menos, a um acontecimento (que ocorreu), a um mito (lugar-dito) ou a uma história (lugar histórico)"(AUGÉ, 2012, p. 77).
} 
se cria na própria dinâmica do gênero e em seu desenvolvimento na história do cinema no Brasil. No caso de Viajo porque preciso, volto porque te amo, ao mesmo tempo em que o início da narrativa deixa evidentes os elementos do filme de estrada, ${ }^{3}$ também coloca, desde o princípio, a amplitude que se pode alcançar na articulação entre essa forma e a representação do sertão.

Para Sara Brandellero (2015), o filme de 2009 cria uma imagem do nordeste em diálogo com o sertão representado anteriormente no cinema, dando azo a uma espécie de redimensionamento metafórico. Na imagem do sertão que se desenha em Viajo porque preciso, duas camadas de tempo se sobreporiam, criando uma visão em perspectiva por meio da qual presente e passado se entrelaçam. Esvaziado de seu sentido utópico ou sem a perspectiva da revolução possível, o sertão é o espaço em que o tempo se congela, território que permanece alheio à modernização e, em larga medida, à estruturação de meios de vida levada a cabo pela urbanização.

Diante dessa interpretação que, no limite, situa no tempo presente a figuração de um sertão arcaico, com modos de vida presos à falta de recursos e à ausência de oportunidades, mas que é marcado pela lógica do consumo trazida pela televisão, é importante que se coloque em questão a forma do road movie de Karim Aïnouz e Marcelo Gomes sob a perspectiva do esfumaçamento dos limites entre o documentário e a ficção. Retomando a gênese do filme nas imagens realizadas em 1997 e no documentário que o antecede em Sertão de acrílico azul piscina, a perspectiva subjetiva criada pela voz narrativa sobreposta ao documental instaura o domínio do ficcional sobre o dado de realidade, o que projeta um fato peculiar para esta discussão, uma vez que esse real é justamente o retrato do sertão. Se a edição das imagens encontra, no formato road movie, substrato profícuo para o processo de narrativização do documental, o modo como se dá a construção do personagem José Renato é decisivo na representação da realidade aqui posta. Note-se, nesse caso, que a metáfora do reencontro do geólogo com a vida constrói-se somente ao final, fora do sertão, com a cena dos mergulhadores de Acapulco que encerra o filme (VIAJO..., 2009).

Nesse ponto, a imagem do mar na sequência que fecha a narrativa de Viajo porque preciso, volto porque te amo serve como ponto em que a ressemantização do sertão entra em evidência e faz o passado e o presente do cinema confluírem: em Deus e o diabo na terra do sol, a sequência final se constrói justamente a partir da descontinuidade (XAVIER, 2007, p. 90) entre a cena em que Manuel corre sobre

3 Em discussão sobre o gênero road movie no Brasil, Samuel Paiva apresenta as suas matrizes a partir da observação de Walter Moser: "imagens de um veículo em movimento, transportando seres humanos por uma estrada; uma iconografia relevante do veículo e da infraestrutura que o faz funcionar; paisagens abertas, com poucas marcas de civilização; um protagonista em exílio acompanhado de uma segunda pessoa com quem forma um casal pelo menos durante uma parte do caminho; uma sequência narrativa com três momentos de intensidade (pegar a estrada, estar na estrada, pegar a estrada novamente); uma modalidade narrativa que expressa uma condição contingente do protagonista; uma interação de mídias que frequentemente põe em cena o rádio instalado no veículo" (PAIVA, 2009. p. 3). 
a caatinga e a imagem do mar, que substitui o espaço do sertão a partir de um corte, sob a trilha sonora que reitera que "o sertão vai virar mar".

A partir do trabalho de citação, o mar de Acapulco e a figura dos mergulhadores colocam em primeiro plano a perspectiva subjetiva que determina a representação do sertão em Viajo porque preciso, volto porque te amo e que já estava anunciada na escolha da voz e do foco narrativos em primeira pessoa, centrados em um personagem sem corpo que institui a camada de ficção sobre o dado real, como já se falou. Enquanto em Glauber Rocha a relação sertão-mar aponta para um tempo futuro em que a revolução se fará possível - seja pela história, seja pelo destino -, no filme de Karim Aïnouz e Marcelo Gomes essa mesma relação não aponta para qualquer perspectiva utópica relacionada a um mundo melhor, mas para um "mergulho" que circunscreve o futuro ao domínio da experiência individual.

É na convivência de tempos que se tem, por fim, a síntese do modo de representação levado a cabo pelo road movie de 2009, especialmente quando se leva em conta a relação entre realidade e ficção aqui já discutida. Na filmagem do material que comporia o documentário sobre as férias nordestinas, diretores e equipe técnica encontram um sertão cuja realidade se dá pelo contraste:

\begin{abstract}
Desconstruímos um monte de clichês que nós próprios tínhamos sobre o sertão. Fomos desconstruindo a romantização do sertão aos poucos, compreendemos que o sertão não é só aquele sertão arcaico, quase mitológico. O sertão também é uma feira do Paraguai que tá ao lado da feira de Caruaru. O sertão também é uma garota que usa botas roxas com aquele calor pra ficar parecida com a Xuxa. O sertão é mais que uma casinha de barro com moradores levando uma vida simples. Por trás daquela simplicidade existe uma complexidade muito grande. [...] É romântico morar num lugar esquecido pelo desenvolvimento econômico, pela classe política, com um clima extremamente árido, onde se anda horas pra se conseguir água potável e cozinhar um feijão? É uma vida dura (BERNADET, 2010).
\end{abstract}

No filme, viajando por esse sertão, José Renato é o olhar da ciência e do progresso que cruza a estrada e se encontra com a possibilidade de uma nova vida, mergulhando em si mesmo. Esse olhar, porém, deixa o sertão para trás, "esquecido", para ser lembrado em uma narrativa.

\title{
A narrativa literária contemporânea: o sertão e seus des- locamentos
}

Livro dos homens, de Ronaldo Correia de Brito, foi publicado em 2005, pouco menos de um ano depois das observações de Walnice Nogueira Galvão sobre a matriz temática sertaneja no cinema e na literatura aqui mencionadas. Antes disso, a Cosac Naify já havia trazido para a cena literária contemporânea o livro Faca, de 
2003. Juntos, os dois livros apresentam 24 contos, em edições com projeto gráfico bem acabado - no caso de Faca, o volume é ilustrado com imagens que transpõem a técnica da xilogravura e as ilustrações de cordel; em Livro dos homens, cada capítulo é separado por um símbolo relacionado ao imaginário sertanejo, o que não deixa de remeter às edições da José Olympio para as narrativas rosianas. Já no primeiro acesso do leitor aos livros, o sertão aparece por meio de uma referência visual, funcionando como um elemento importante na medida em que irá se projetar como referência semântica na leitura dos contos.

Em "Milagre em Juazeiro", de Livro dos homens, o sertão faz parte da trajetória percorrida pelos personagens em peregrinação de Recife a Juazeiro e é também terreno simbólico cuja tradição é colocada em questão pelo olhar cético da ciência e do desenvolvimento econômico. Na narrativa, Maria Antônia e seu marido Afonso, ambos médicos que moram na capital de Pernambuco, viajam em um caminhão de romeiros para participar da festa de Padre Cícero, cumprindo um pedido do pai de Antônia que em seu leito de morte revelou a ela a história da família e, com ela, a possibilidade de a avó, a quem nunca vira, morar em Juazeiro. Viajar com a romaria foi um desejo de Maria Antônia, o que irritava o marido, pouco afeito aos costumes populares e em nada próximo à crença do povo.

A narrativa organiza-se em vinte quadros curtos - pequenos sketches narrativos em que predomina o discurso direto - seguidos por um episódio mais longo, contrastante pela extensão e pela fala predominante do narrador. A sucessão de quadros constrói-se pela oscilação de cenas que ora focalizam a conversa que Maria Antônia teve com o avô momentos antes de sua morte, ora presentificam a viagem para Juazeiro, com os diálogos entre Antônia, Afonso e os romeiros; o que já ocorre no quadro que abre o conto:

- Valhei-me, Nossa Senhora, valhei-me! - cantaram as peregrinas num pedido extremo de socorro. Naqueles desertos de sertões, o vento arrastou os cantos para as profundezas da terra, onde guardavam-se as vozes de todas as mulheres do mundo, desde as mais antigas eras, retornando com o seu eco (BRITO, 2005, p. 67-68).

A presentificação, promovida nesse caso pelo uso do discurso direto, coloca em perspectiva três tempos distintos: o tempo presente, aquele em que o casal viaja com os romeiros; o passado da família de Maria Antônia, com a história de abandono contada pelo avô; o passado do sertão, que entra em cena por meio da tradição da romaria, pela fé das beatas e pela festa que, ao final, se configura como o espaço em que Antônia, perdida no calor da devoção do outro, reconhece-se nos rostos que a cercam.

No presente o sertão aparece como "deserto", em referência que retoma um dos paradigmas de representação desse espaço na história da literatura brasileira, em que é terra longínqua, distante da civilização ou de eixos urbanizados com estrutura, saneamento e conforto. Essa perspectiva ganha vulto com o contraste criado 
pela figura de Afonso: embora formado na mesma escola de medicina da esposa, o personagem delimita um ponto de vista marcado ideologicamente pela profissão que exerce, reafirmando o ceticismo de quem não acredita na fé e permanece indiferente ao sertão. Com febre e manchas pelo corpo, sintomas que se agravam ao longo do percurso, Afonso recusa-se a receber qualquer ajuda das romeiras, seja o chá de erva-cidreira, seja o alento de uma oração. Enquanto o marido dorme, porém, e conforme a comitiva adentra no sertão rumo a Juazeiro, Maria Antônia deixa-se conduzir pela atmosfera de devoção e, assustada, faz uma promessa a Padre Cícero para que o marido melhore, oferecendo como paga pela graça a garantia de que Afonso se ajoelharia em agradecimento, vestido de franciscano:

Sabia que ele [Afonso] enfrentava a viagem para estar ao seu lado, por temor de perdê-la. Com um pressentimento sombrio, ela fez a promessa que a velha da Irmandade da Boa Morte sugerira. Não acreditava que o marido fosse pagá-la, pedia por sua própria conta, com fé de romeira. [...] Assustada, buscou um referencial de cidade que lembrasse o Recife deixado para trás (BRITO, 2005, p. 78).

Conforme Recife é "deixado para trás", Maria Antônia adere de maneira mais decisiva à crença das romeiras. Sob o signo do sagrado, o sertão impõe seu imaginário e, no presente, determina as ações da personagem, que deixa o marido em um hotel na cidade de Juazeiro e, à procura de sua avó, mistura-se à multidão. Entre as pessoas, sem individualizar-se porque anônima na massa de fiéis, coloca em evidência a sobrevivência do passado na força da tradição.

A narrativa de Ronaldo Correia de Brito que compõe Livro dos homens constrói um sertão contemporâneo em que a convivência de diferentes temporalidades rasura o espaço por meio dos sentidos que a ele são impressos pelas experiências individual e coletiva. As romarias a Juazeiro do Norte em louvor a Padre Cícero podem ser tomadas como uma prática que dá sentido ao deslocamento espacial por meio da penitência que, no imaginário cristão, funciona como meio para que se obtenha uma graça ou como demonstração de entrega pela fé, como Cristo fizera em seu sacrifício.

Com mais de seiscentos quilômetros, a viagem de Recife a Juazeiro do Norte, no Ceará, pode ser feita por via aérea - a cidade cearense possui aeroporto com terminal de passageiros desde a década de 1980, tendo sido integrado à rede da Infraero em março de 2012 - ou por via terrestre. As romarias acontecem em caminhões mal adaptados para o transporte de passageiros - os "paus de arara" e fazem o percurso em um tempo relativamente longo e sem condições de segurança ou qualquer conforto. De uma maneira geral, a utilização desse meio de transporte está atrelada ao baixo poder aquisitivo dos peregrinos, para quem representa a única opção.

Ao tratar daquilo que chama de "escândalo do turismo", Marc Augé (2010, p. 69) observa nos catálogos de empresas de turismo a figuratividade da "ubiquidade" 
e da "instantaneidade", experiência restrita às camadas mais altas da sociedade. Considerando a perspectiva do antropólogo em relação ao deslocamento contemporâneo, é possível tratar da existência de diferentes relações do sujeito com o espaço e com o tempo a partir do acesso que possui, ou não, às formas de mobilidade. Se a viagem de Recife a Juazeiro do Norte tem cerca de uma hora de duração em um voo sem escalas ou conexões, a peregrinação pode levar mais de vinte e quatro horas, conforme o estado de conservação do caminhão. No primeiro caso, Recife-Juazeiro estão separadas por dois aeroportos; no segundo, por uma estrada que atravessa o sertão e seus imponderáveis, passando por pequenas cidades em que a carência material das margens se confunde com a pobreza dos passageiros.

A personagem Antônia escolhe o caminhão como modo de se aproximar do povo e, assim, insere-se em uma lógica espaço-temporal que é condicionada por esse dado material de mobilidade:

Antônia sorriu, fechando o depósito térmico. Ao longo da viagem fora distribuindo os alimentos e a água para ela e o marido. Nas cidades onde paravam, não havia água potável, nem mesmo para quem pudesse comprála. Afonso reclamava da mulher, que nem esperava que pedissem e já oferecia o que tinham (BRITO, 2005, p. 77).

Outro condicionamento deve ser considerado, também, na experiência de Antônia ao cruzar o sertão: como prática cultural, a romaria constrói uma articulação entre tempo e espaço que se relaciona com a dimensão subjetiva daquele que cruza o caminho. Seja pelo sofrimento, seja pela devoção ou pelo agradecimento, é da ordem do simbólico o sentido que se cria entre aquele que transita e a espacialidade ou, ainda, entre o tempo da jornada e o encontro com o sagrado: "Cada aspecto, cada detalhe desse lugar tem um sentido que só é inteligível para os membros do grupo, porque todas as partes do espaço que ele ocupou correspondem a outros tantos aspectos diferentes da estrutura e da vida de sua sociedade" (Halbwachs, 2006, p. 159-160).

Enquanto Afonso permanece alheio ao grupo, ansiando pelo retorno em "ônibus de linha”, Antônia integra-se ao domínio coletivo e é justamente essa integração que determina o desenvolvimento da narrativa. Na parte final do conto, a médica caminha pela festa de Juazeiro, perguntando para moradores e comerciantes sobre o paradeiro de Antônia Praxedes, sua avó. Sem qualquer referência, desiste de perguntar e se senta na Igreja do Socorro junto aos fiéis para ouvir a pregação de um padre. Diante dos gritos de que a igreja estaria pegando fogo, corre abraçada às mulheres que com ela rezavam e se encontra com o que viera buscar: "Tomada de alegria, banhada de lágrimas, foi capaz de reconhecer Antônia Praxedes em todos aqueles rostos" (Brito, 2005, p. 83-84).

A narrativa termina com a sugestão de que Antônia teria visto, entre os fiéis, seu marido vestido de franciscano. A composição de um desfecho em aberto, recorrente na produção de Ronaldo Correia de Brito, deixa em suspensão o que 
teria acontecido a Afonso - se conseguiu se recuperar da doença no hotel, se efetivamente morreu, como temia a esposa -, mas reafirma o olhar e a experiência de Maria Antônia: depois de reconhecer a avó na imagem das mulheres que peregrinam todos os anos e rezam sob as bênçãos de Padre Cícero, com os olhos ofuscados pela claridade, a personagem interpreta o que vê a partir de suas expectativas ou de dentro do seu novo modo de significar a realidade: ao encarar o passado da família, o que se (re)define é o sentido do presente.

"Milagre em Juazeiro" constrói, na viagem de Maria Antônia à procura de sua avó, a narração de um encontro. Por meio da estrada que cruza o sertão, o que se tem é a representação de um espaço significado pela tradição, em uma prática que dá sentido ao caminho ao mesmo tempo em que é significada pela própria estrada. No conto, a viagem coloca em evidência o olhar de Afonso, que não se identifica com os passageiros do caminhão pau de arara e, em seu egoísmo, é incapaz de compartilhar água com o outro. Da figura de Afonso, projeta-se o contraste com um sertão carente de quase tudo, com cidades à margem do desenvolvimento econômico e tecnológico, sem água potável. Ao lado de pessoas para quem a pouca comida faz parte de um modo de vida cotidiano, o médico autocentrado é a imagem síntese do olhar externo, que não vê a desigualdade ou prefere dela não partilhar para cuidar de si mesmo.

Também é de síntese a representação do sertão promovida pela narrativa. Em leitura da obra de João Guimarães Rosa, Maria Célia Leonel (2010) analisa a evolução semântica da palavra "sertão" entre os poemas de Magma e os contos de Sagarana, apontando, em uma de suas conclusões, para um desenvolvimento que vai do "noológico ao cosmológico": nos poemas e em alguns contos do livro de 1946, "sertão" é o espaço que está longe do falante ou faz referência a zonas não povoadas, afastadas da civilização, enquanto em "A hora e vez de Augusto Matraga" já se delineia a transformação que, em Grande sertão: veredas, fará do sertão qualquer lugar ou o que está em toda parte: "O senhor tolere, isto é o sertão. Uns querem que não seja: que situado sertão é por os campos-gerais a fora a dentro, eles dizem, fim de rumo, terras altas, demais do Urucuia. Toleima. Para os de Corinto e do Curvelo, então, o aqui não é dito sertão? Ah, que tem maior!" (RosA, 198o, p. 9).

Na narrativa de Livro dos homens, o sertão é o espaço cruzado pela estrada, "desertos sertões", "aquele mundo estranho" para quem deixara Recife para trás. Além disso, o sertão é o domínio do encontro, o dentro da gente em que Riobaldo conheceu o amor. O mítico do sertão, aqui, é marcado pela carência material de um território que permanece à margem do progresso, de modo que a síntese se dá justamente no cruzamento dessas duas perspectivas, por onde se antevê o geográfico, espacialidade rasgada por transportes precários e regulamentados nas dobras da lei, dos quais os pobres dependem para se locomover, ${ }^{4}$ mas também o imaginário

4 Desde 2012, partindo da Resolução nº 2 , de 19 de novembro de 1998, do Conselho Nacional de Trânsito (Contran), o governo do estado do Ceará regularizou o transporte de passageiros em veículo de carga, os chamados caminhões paus de arara, autorizando a circulação dos veículos 
da fé que insere, no sertão contemporâneo, a experiência subjetiva em que o passado ressignifica o presente.

Com buzinas disparadas, cobertos por bandeiras coloridas, caminhões de romeiros cruzam o carro de José Renato, com pessoas espremidas, outras dependuradas, sorridentes, acenando para a câmera. Em um deles, em faixa afixada na lateral, lêse a origem dos peregrinos: "Guaxuma - Maceió - Alagoas". A perspectiva da fé é marcada na narrativa pelo som estridente das buzinas, entrecortado por palmas e cantos, o que faz a cena ser invadida pelo ritmo - e, no limite, pelo tempo - dos romeiros. O destino dos diferentes paus de arara é informado pelo personagem, que decide também ir a Juazeiro para desviar da solidão da viagem: "Saí fora da rota, precisava ver gente. A cidade dos romeiros sempre tá cheia de gente" (VIAJO..., 2009).

As romarias também fazem parte do sertão de Viajo porque preciso, volto porque te amo, aqui vistas pelo olhar de José Renato, que poderia coincidir com a perspectiva de Maria Antônia, a médica que se mistura aos fiéis para se encontrar. Nos olhos de uma romeira filmada com a cabeça para fora do caminhão, Maria Antônia teria encontrado Antônia Praxedes: pele queimada de sol, emocionada e com um sorriso tímido para a câmera, escondendo parte do rosto e os poucos dentes que tinha para exibir, anônima, a figura da mulher que, no filme, mostra-se aos 18 min e 29 s, pode ser a metáfora da experiência subjetiva que dá sentido à estrada no caminho ao milagre que, no conto, se dá em Juazeiro. Poder-se-ia mesmo dizer que a narrativa de Ronaldo Correia de Brito e o filme de Karim Aïnouz e Marcelo Gomes encontram-se no ponto exato em que essa figura, com o vento batendo no rosto, preenche toda a tela e, com um fundo musical melancólico, dá a dimensão do sujeito naquele espaço-tempo.

Como se disse, no cinema de Viajo porque preciso, o sertão não é a revolução anunciada pelo mar visto de cima que invade a cena final do filme de Glauber Rocha: o mar, aqui, coloca na tela outro anúncio: o de que o sertão agora é visto por um sujeito que mistura ao espaço o domínio da sua experiência. Assim como na literatura, a espacialidade do sertão é vista em profundidade, em uma representação que não esconde a pobreza e a marginalização do presente, mas a mistura ao imaginário de um passado que permanece.

Lado a lado, o filme e o conto propõem que a presença da matriz sertaneja na literatura e no cinema brasileiros contemporâneos não depende de um olhar atávico ou anacrônico para o passado, nem tampouco se configura como recusa de enfrentar o futuro. Se a estrutura do road movie favorece a perspectiva revisionista que aqui se comentou e se vale de uma "vocação para o real" (PAIVA, 2014) que fundamenta o gênero cinematográfico, e em larga medida, o conjunto da ficção

desde que atendam a municípios que não possuem transporte coletivo ou com demanda superior à estrutura de transporte nos locais em que ele existe. A mesma resolução, no Item III do segundo parágrafo de seu segundo artigo, torna possíveis as viagens intermunicipais "por motivos religiosos, quando não houver condições de atendimento por transporte de ônibus”. 
de Ronaldo Correia de Brito, não permitiria uma análise dessas duas narrativas tomando o sertão em termos de diluição. Estrada e deslocamento, recorrentes na literatura e no cinema brasileiro que, nas últimas décadas, fazem uso da cultura sertaneja como matriz, funcionam como operadores que articulam a natureza das duas formas: filme e conto, possibilitando a recuperação de temas e a proposição de novos olhares. Em tempos em que se reinventa, o sertão viaja - porque precisa (?) - para de si ter uma nova imagem.

\section{Referências}

AugÉ, Marc. Não lugares: introdução a uma antropologia da supermodernidade. 9. ed. Campinas: Papirus, 2012.

AugÉ, Marc. Por uma antropologia da mobilidade. Maceió: Edufal; São Paulo: Editora da Unesp, 2010.

Bernadet, Jean-Claude. Entrevista Marcelo Gomes e Karim Aïnouz - Primeira parte. Blog pessoal, [S.l.], 6 maio 2010. Disponível em: http://jcbernardet.blog.uol. com.br/arch2010-05-02_2010-05-08.html. Acesso em 12 jun. 2016.

BRANDELlERo, Sara. Viagens, memórias e sertão no road movie contemporâneo: o caso de Viajo porque preciso, volto porque te amo. Palestra proferida na Universidade Federal de São Carlos, São Carlos, 8 jun. 2015. (informação verbal)

Brito, Ronaldo Correia de. Livro dos homens. São Paulo: Cosac Naify, 2005.

Galvão, Walnice Nogueira. A ilha do dia anterior. Folha de S. Paulo, São Paulo, Caderno Mais!, p. 5, 31 out. 2004a.

Galvão, Walnice Nogueira. Metamorfoses do sertão. Estudos avançados, São Paulo, n. 18, v. 52, p. 375-394. 2004b.

Halbwachs, Maurice. A memória coletiva. Tradução de Beatriz Sidou. São Paulo: Centauro, 2006.

Leonel, Maria Célia de Moraes. Guimarães Rosa: magma e gênese da obra. São Paulo: Editora da Unesp, 2010.

PaIva, Samuel. A propósito do gênero road movie no Brasil: um romance, uma série de TV e uma estrada. Revista rumores, São Paulo, v. 3, n. 6, p. 1-11, set./dez. 2009.

PAIVA, Samuel. Gêneses do gênero road movie. Significação, São Paulo, n. 36, p. 3553, 2011.

PAIva, Samuel. O deslocamento do sujeito masculino no sertão contemporâneo: estudos de caso na literatura e no cinema. In: Vicente, Adalberto Luis; JunQUeIRA, 
Renata Soares (Org.). Teatro, cinema e literatura: confluências. São Paulo: Cultura Acadêmica, 2014. p. 75-90.

RosA, João Guimarães. Grande sertão: veredas. 14. ed. Rio de Janeiro: José Olympio, 1980.

VIAfO porque preciso, volto porque te amo. Direção: Marcelo Gomes; Karim Aïnouz. [S.1.]: Rec Produtores Associados, 2009. 1 DVD (75 min).

XAvier, Ismail. Alegorias do subdesenvolvimento: cinema novo, tropicalismo, cinema marginal. São Paulo: Cosac Naify, 2012.

XAvier, Ismail. Sertão mar: Glauber Rocha e a estética da fome. São Paulo: Cosac Naify, 2007.

Recebido em 5 de novembro de 2017.

Aprovado em 25 de março de 2018.

\section{Resumo/Abstract/Resumen}

\section{Narrativas de estrada e o sertão na literatura e no cinema brasileiros con- temporâneos}

\section{Juliana Santini}

Este trabalho realiza uma reflexão em torno da representação do sertão em Viajo porque preciso, volto porque te amo, filme de Marcelo Gomes e Karim Aïnouz, e no conto "Milagre em Juazeiro", de Ronaldo Correia de Brito. A questão proposta é de que os elementos da narrativa de estrada articulam-se, nos dois casos, a uma revisão dos significados assumidos por essa imagem em diferentes momentos da história da literatura e do cinema brasileiros.

Palavras-chave: sertão, deslocamento, narrativas de estrada.

\section{Road narratives and hinterland in Brazilian contemporary literature and cinema}

\section{Juliana Santini}

This work presents an analysis of Viajo porque preciso, volto porque te amo, a motion picture by Marcelo Gomes e Karim Aïnouz, and "Milagre em Juazeiro", a short story by Ronaldo Correia de Brito. The proposed question is how the characteristics of road narratives are related, in both cases, to a revision of the meanings assumed by hinterland during different periods in Brazilian literature and cinema.

Keywords: hinterland, displacement, road narratives. 
Narrativas de carretera y el sertón en la literatura y el cine brasileño contemporáneos

\section{Juliana Santini}

Este trabajo realiza una reflexión en torno de la representación del "sertão" en $V i$ ajo porque preciso, volto porque te amo, una película de Marcelo Gomes y Karim Aïnouz; y en el cuento "Milagre em Juazeiro", de Ronaldo Correia de Brito. La cuestión propuesta es que los elementos de la narrativa de carretera se articulan, en ambos casos, en torno a una revisión de los significados asumidos por esa imagen en diferentes momentos de la historia de la literatura y del cine brasileños contemporáneos.

Palabras clave: sertón, desplazamiento, narrativas de carretera. 